\section{Management of myocardial infarction in Scotland: have clinical trials changed practice?}

Acute myocardial infarction remains one of the most common indications for emergency admission to hospital. During the past two decades the main changes in management have been the widespread introduction of coronary care units and the trend towards earlier ambulation. The use of prophylactic antiarrhythmic treatment and long term anticoagulant drugs has declined.

Recent studies have suggested a number of further management options in the acute and convalescent phases of myocardial infarction, such as $\beta$ blockade, thrombolytic treatment, antiplatelet agents, and the use of exercise testing to identify high risk individuals. ${ }^{1}$ These studies have been discussed extensively in both cardiological ${ }^{2}$ and general medical ${ }^{3}$ journals. The aim of this study was to assess the impact of such trials (and reviews) on hospital practice.

\section{Methods and results}

A questionnaire was sent to 160 consultant physicians practising in Scotland. names were obtained from the membership list of the Scottish Society of Physicians, which includes most Scottish physicians. In addition to questions relating to management of infarction (table), details of age and specialist interest were sought.

The $\chi^{2}$ test was used to assess the significance of the results.

Replies were received from 128 consultants (80\% response rate), 69 of whom (54\%) were based in teaching hospitals. Thirty six $(28 \%)$ were cardiologists or physicians with an interest in cardiology. The median period of bed rest recommended for patients who have suffered a myocardial infarction was three days (mean 3.1 days). Although the mean period of bed rest recommended increased with the age of the physician, the differences were not significant. The table shows the number of respondents who use exercise testing and $\beta$ blockers in patients who survive myocardial infarction.

Use of $\beta$ blockers and exercise testing in the management of survivors of myocardial infarction by physicians and by cardiologists. Figures are numbers (percentages) of doctors

\begin{tabular}{lcc}
\hline & $\begin{array}{c}\text { Cardiologists } \\
(\mathbf{n}=36)\end{array}$ & $\begin{array}{c}\text { Physicians } \\
(\mathbf{n}=92)\end{array}$ \\
\hline$\beta$ blockers & $21(58 \cdot 3)$ & $29(31)$ \\
Exercise testing & $23(64)$ & $23(25)$ \\
Both & $16(44 \cdot 4)$ & $12(13)$ \\
Neither & $8(22 \cdot 2)$ & $52(56 \cdot 5)$ \\
\hline
\end{tabular}

${ }^{\star} \mathrm{p}<0.01$.

\section{Comment}

The results of this survey show significant differences in the management of patients who have suffered a myocardial infarction by physicians and cardiologists, particularly with respect to the use of $\beta$ blockade and exercise testing. A previous survey of British cardiologists showed that most of them (72\%) prescribed $\beta$ blockers after myocardial infarction, suggesting that this approach had become accepted in clinical practice. ${ }^{4}$ Although our series included fewer cardiologists, the majority (58\%) also prescribed $\beta$ blockers. Most patients who survive a myocardial infarction are managed by general physicians, however, who seem to be less enthusiastic about this treatment.

Treatment of all survivors of myocardial infarction with $\beta$ blockers would mean that a number of individuals at low risk of further cardiac events would be treated, probably without benefit. It is generally agreed that $\beta$ blockers reduce annual mortality by about $20 \%$; however, studies have not shown conclusively which patients benefit most. Thus treatment of all patients without contraindications has been advocated. As a large number of patients need to be treated to reduce mortality from $10 \%$ to $8 \%$, the concept of risk stratification has arisen with the aim of identifying high risk groups who would benefit from treatment and excluding low risk groups whose already good prognosis would not be significantly improved. Several management schemes using exercise testing have been suggested. Our findings indicate, however, that most physicians use neither $\beta$ blockers nor exercise testing.

Although reservations have been expressed about the safety of early mobilisation, our survey confirms that this policy is widely adopted. In the current setting of shortage of beds and attempts at cost cutting in hospitals it is perhaps understandable that such an approach has been generally accepted.

We do not wish to imply that there is an ideal method of treating patients who have suffered a myocardial infarction. Survivors of infarction are a heterogeneous group. There is no general agreement on how such patients should be managed, and it seems unlikely that there ever will be. At present, $\beta$ blockers and exercise testing appear to be used more widely by cardiologists than by general physicians.

We thank our colleagues who took the trouble to respond to the questionnaire.

I Theroux P, Waters DD, Halphen C, Debaisieux JC, Mizgala HF. Prognostic value of exercise testing soon after myocardial infarction. N Engl $\mathcal{H}$ Med 1979;301:341-5.

Yusuf S, Peto R, Lewis J, Collins R, Sleight P. Beta-blockade during and after myocardial infarction: an overview of the randomised trials. Prog Cardiovasc Dis 1985;27:335-71.

Mitchell JRA "But will it help my patients with myocardial infarction?" The implications of recent rials for everyday country folk. Br Med I 1982-285:1140-8.

4 Baber NS, Julian DG, Lewis JA, Rose G. Beta-blockers after myocardial infarction: have trials changed practice? BrMed J 1984;289:1431-2.

(Accepted 13 Februany 1987)

Department of Medical Cardiology, Royal Infirmary, Glasgow G31 2ER STEPHEN J HUTCHISON, MRCP, registrar

STUART M COBBE, MD, FRCP, professor

Correspondence to: Dr Hutchison.

\section{Long term effect of oestrogen replacement therapy on bone mass as measured by dual photon absorptiometry}

Long term oestrogen replacement therapy prevents postmenopausal bone loss when started soon enough after loss of ovarian function. ${ }^{12}$ Dual photon absorptiometry with gadolinium-153 uses two energy levels and allows for soft tissue interference. It also permits measurement of bone mass in areas that were previously less well examined-for example, lumbar spines and the femoral neck. Measurement at one site gives limited information about density at other sites. ${ }^{3}$

There is no direct information in previous reports about long term effects of oestrogen on vertebral mineral content, and there are no data at all about any potential effects on bone in the neck of the femur. To address these issues we measured bone mass in the lumbar spines and femoral neck of patients participating in a long term controlled study of the effects of oestrogen in women after oophorectomy. ${ }^{124} \mathrm{We}$ report here the long term effect of oestrogen on bone mass at the major fracture sites in postmenopausal osteoporosis.

\section{Patients, methods, and results}

Twenty five consecutive patients at our clinic who were still participating in the placebo arm of the study (years since menopause $=15 \cdot 8($ SD 2.3)) and an equal number of patients receiving mestranol (years since menopause $=14.9(2.5)$ agreed to participate in this study. No attempt was made to match the patient groups, consecutive attendance being the sole requirement for entry to the study. All patients had had oophorectomy premenopausally. To show that the groups were representative of the original study population they were compared with the patient groups reported on previously. ${ }^{1}$ As there were no significant differences in height, weight, age at operation, or original measurements of bone mass we considered that the groups reported on here were typical of the parent population. The average daily dose of mestranol was $26 \mu \mathrm{g}$.

The bone mineral content of the lumbar spines (L2-L4) and right femoral neck was estimated by dual photon absorptiometry (DP3, Lunar Radiation Corporation, Wisconsin). The coefficient of variation of the technique obtained by triplicate estimates in 24 women was $1.7 \%$ within the ranges of bone mass reported here. The significance of differences in mean values was determined with Student's $t$ test as bone mass is normally distributed within age groups.

The mean number of years of treatment was similar in both groups. The table

Comparison of bone mineral density $\left(\mathrm{g} / \mathrm{cm}^{2}\right)$ in 25 women given mestranol and 25 given placebo. Values are means $(S D)$

\begin{tabular}{|c|c|c|c|c|}
\hline \multirow{2}{*}{$\begin{array}{c}\text { Site of } \\
\text { measurement }\end{array}$} & \multicolumn{2}{|c|}{ Treatment } & \multicolumn{2}{|c|}{ Significance } \\
\hline & Mestranol & Placebo & $t$ & $\mathbf{p}$ \\
\hline $\begin{array}{l}\text { Lumbar spines (L2-L4) } \\
\text { Femoral neck } \\
\text { Ward's triangle } \\
\text { Greater trochanter }\end{array}$ & $\begin{array}{l}1.17(0.16) \\
0.87(0.13) \\
0.77(0.15) \\
0.71(0.14)\end{array}$ & $\begin{array}{l}0.94(0.13) \\
0.77(0.10) \\
0.64(0.13) \\
0.68(0.12)\end{array}$ & $\begin{array}{l}5 \cdot 5 \\
2 \cdot 9 \\
3 \cdot 1 \\
0 \cdot 72\end{array}$ & $\begin{array}{l}<0.001 \\
<0.01 \\
<0.01 \\
\quad \text { NS }\end{array}$ \\
\hline
\end{tabular}

